Pryymenko, SA., Burla OA. Functional process decomposition as a method of management of energy product lifecycle. The International Scientific Journal

"Mechanism of Economic Regulation". 2020; 2: 129-135.

\title{
Functional process decomposition as a method of management of energy product lifecycle
}

(This work was supported by the Ministry of Education and Science of Ukraine (Project No. 0119U100766 «The optimization model of smart and secure energy grids building: an innovative technologies of enterprises and regions ecologisation»)).

\section{S.A. Pryymenko1, O.A. Burla2}

To achieve greater management efficiency of any system, it is necessary to create the overall effectiveness of all its components. Taking into account the fact that the anthropogenic load on the environment and the magnitude of environmental and economic costs of the first stage of the lifecycle of the energy product depend on the cause and effect relationships at (i-n) stages, one should mention the ecologically oriented management system of the energy product lifecycle. An ecologically oriented management system of the energy product lifecycle is a management system that ensures environmental safety at each stage by coordinating the production and environmental functions and processes of energy entities. The process of environmental management, which is considered to be a process associated with compromises between socioeconomic and environmental needs of society in terms of limited resources, should include the objectively existing interaction between society and nature, features of modern social development, causation and environmental and economic contradictions [5]. For example, from the standpoint of economic feasibility, this task resolves itself into such a level of environmental costs that would cause minimal environmental and economic losses.

Key words: lifecycle, power plant, ecologically oriented management, decomposition.

УДК 005.41:502/504

JEL коди A11, H56, L10

\section{Introduction.}

Energy product lifecycle management is a development strategy that takes into account three factors interconnected and effect relationships of the subsystems such as: economic feasibility, environmental impact and social impact. The problem of balancing such a system is the wave-like economic development, its long and short cycles. For example, during the period of economic growth the demand for electricity increases, and hence for natural resources, therefore, the level of environmental pollution increases as well, suppressing the assimilation potential at the same time. In such cases, environmental activities do not provide sufficient environmental protection due to the slow pace of their development referred to the rapid economic growth. Otherwise, reducing the consumption of natural resources leads to reduction of emissions. But the rate of reduction of emissions into the environment is much lower than the rate of reduction of economic activity. Such scientists as V.O. Barinova, E. Benz, D. Dzhevel, O.F. Balatsky, V.V. Zhdanov, Yu. O. Landau and A.K. Shidlovsky dealt with the issues of product lifecycle management $[2,4,5,6]$,. The analysis of the scientific works of the authors mentioned above shows that most studies are based mainly on economic and social indicators of the industry, without examining the lifecycle of the energy product as a whole, taking into account environmental factors. The relationship between environmental and economic components in the lifecycle stages of an energy product has not been taken into account [3].

1Svitlana A. Pryymenko - PhD in Economics, Assistant of the Department of Public Health of Medical Institute, Sumy State University; 
2Oksana A. Burla - PhD in technical sciences, assistant of the Department of Applied Ecology, Sumy State University.

The aim of the article is to study theoretical approaches to ecologically oriented management of the lifecycle of an energy product to ensure environmental, and natural-technogenic safety. According to the aim, the following tasks have been defined:

- to explore the concept of environmentally oriented management of the lifecycle of an energy product;

- to substantiate the conceptual principles of functional process decomposition of the system of ecologically oriented management of the energy product lifecycle.

Research results. The implementation of the concept of sustainable development is carried out through the greening of existing socio-economic relations. Environmentally-oriented management is a type of product lifecycle management the main purposes of which are to define the duration of individual stages of the energy product lifecycle starting from energy generation to waste disposal, identify economic and environmental problems arising from each of them, and forecast relevant costs and effects [5].

The main objectives of ecologically oriented management of the lifecycle of an energy product are stage-by-stage control and timely identification of "weak" stages of the lifecycle of an energy product to prevent the occurrence of environmental and economic losses in the future. Ecological and economic losses are considered as actual ecological, economic and social losses caused by violation of environmental legislation, human economic activity, natural disasters or catastrophes. Losses are detected as the losses of natural, labor, material, and financial resources in the national economy, as well as the deterioration of socio-hygienic conditions of human existence and qualitative changes (losses) of the economic potential of the country [1]. For example, investing in treatment plants in refineries will reduce the environmental and economic costs and losses of power plants running on petroleum products, and increase their efficiency. Otherwise, environmental and economic losses will accumulate during each stage of the product lifecycle and transformed brought to the next stage (Fig. 1).

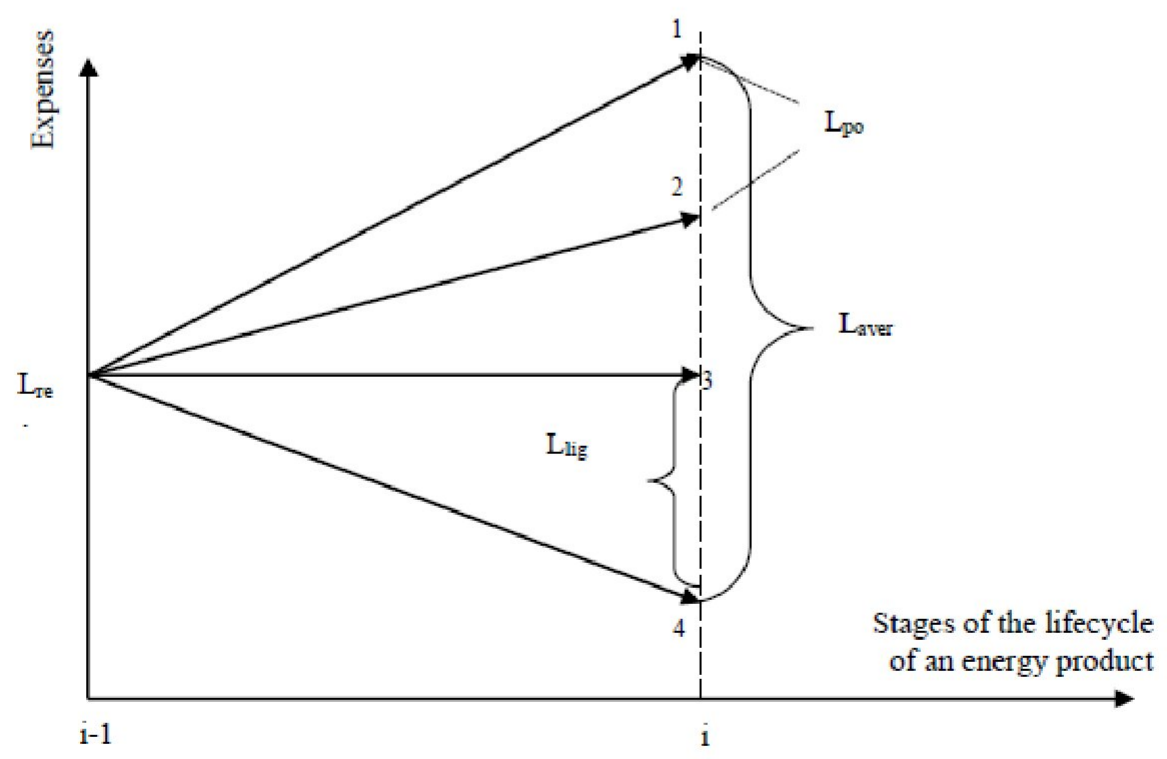

Fig. 1. - The process of transformation of environmental and economic losses from stage (i-1) to the stage $i$ of the lifecycle of an energy product [by author, 3, 5,7]

In Figure 1 we have shown that in the case of environmentally oriented measures at stage (i-1) to prevent (eliminate) environmental and economic losses in the following stages, the losses will be at point 3 or 
4. In case of ignoring environmentally oriented measures at stage (i-1) environmental and economic losses will be cumulative (point 1 or 2). For example, the construction of new filters during the commissioning of a power plant will lead to insignificant environmental impacts in the production of a unit of the energy product. Each stage i should be controlled by the next stage $(i+1)$.

Thus, environmental and economic losses are classified as follows:

- residual (Lred) - environmental and economic losses, the amount of which at the stage $\mathrm{i}$ has not changed regarding stage (i-1);

- possible (Lpos) - environmental and economic losses that can be transformed from stage (i-1) to stage $i$ as a result of inaction of the previous stage in terms of environmentally friendly measures;

- liquidated (Llig) - reduced environmental and economic losses at the stage i regarding stage (i-1);

- averted (Laver) - the difference between possible and actual losses

Having identified the possible environmental and economic consequences at the stage $i$ depending on the activities of the stage (i-1), we can come to the conclusion that, as a result of environmental inaction of energy companies at the stage of resource provision, loss will be accumulated at each subsequent stage and reimbursed directly by electricity producers (power plants). To prevent such a scenario, all management measures of the energy product lifecycle should be consistent in terms of both management functions and processes. Due to this fact, the study of the system of ecologically oriented management of the energy product lifecycle is to be carried out on the basis of functional process decomposition (Fig. 2). Functional decomposition considers the process of managing the energy product lifecycle as a complex system consisting of separate interconnected functional subsystems that take into account the specifics of management decisions at each stage of the lifecycle, whereas the process decomposition allows you to establish the order of management decisions. The first level of functional decomposition is the management of the lifecycle of the technology of energy product generation at the stage of resource provision. The second level of decomposition is the management of the power plant lifecycle, the third is the management at the stage of electricity consumption. For example, in the United States during the energy crises in 1973 and 1979, a number of reforms aimed at reducing energy consumption were developed to implement methods of managing electricity consumption [1]. Firstly, the law on national energy saving policy was adopted. The policy was aimed at reducing the level of electricity consumption through energy saving measures and leveling the load schedule by reducing energy consumption peaks, stimulating demand in the failures of the power system load schedule [4].

The capacity of energy companies can be managed due to the rational use of natural resources, turning to new environmentally oriented production technologies. The quality of the final product depends on the combination of production and management technologies. For example, in the process of developing new technologies for generation of the energy product, current and future consumptions of natural resources are taken into account, which in combination with management functions make it possible to manage the energy product throughout the lifecycle. 


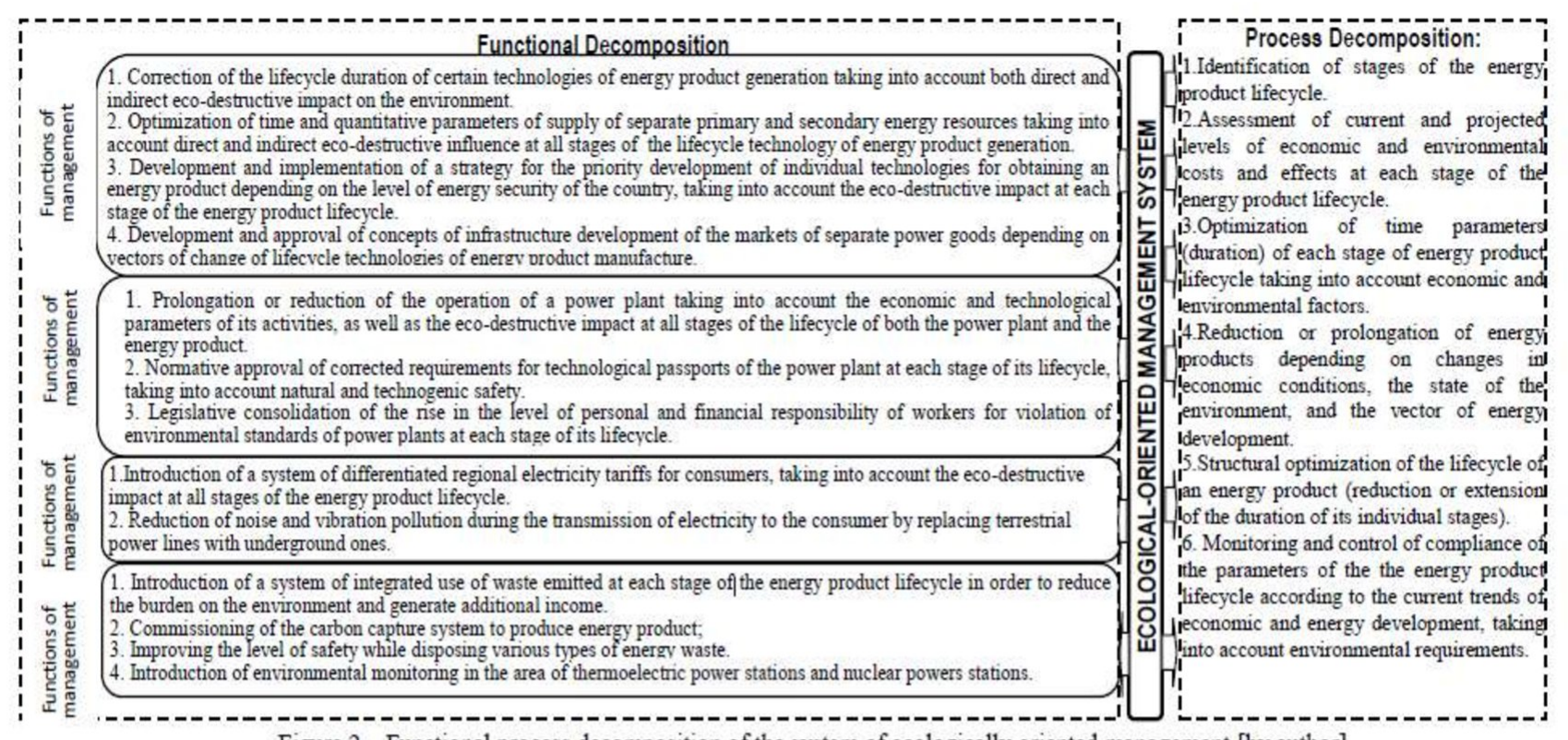

Figure 2 - Functional process decomposition of the system of ecologically oriented management [by author]

Thus, the mechanism of formation of the system approach to ecologically oriented management of a lifecycle of an energy product differs from existing ones by applying a method of process and functional decomposition which allows the following [2]:

1) to establish a clear sequence of management decisions and run business processes within the process decomposition;

2) to take into account the existing ecological and economic relationships within the functional decomposition and to structure the tasks taking into consideration the functional specifics of the object of management.

This allows one to predict all the effects and costs at each stage of the lifecycle of the energy product objectively, to identify chains of cumulative increase in costs to overcome the consequences of ecodestructive influence on each of them, as well as so-called "breakpoints" such as time periods, operations, resources, etc. the probability of uncontrolled or unforeseen environmental losses for which is significant.

Conclusions. To sum up, the basis for ensuring environmentally balanced development of electricity generation is the economic greening of the lifecycle management system. Mankind must realize that the economic development of the country depends on the solution of three main problems: energy generation, the economic condition of the country and the quality of the environment. It is impossible to allow the level of development of the energy complex to increase by ignoring the laws of economics and endangering the state of the environment. The most rational mechanism for ensuring the sustainable development of energy is its greening, which combines all the factors mentioned above. The experience of the world's leading countries (Germany, Holland) shows that the most important issue for the greening of each country's economy is the formation and implementation of mechanisms needed for launching the environmentally friendly energy management system.

\section{References}

1. Energy, electricity and nuclear power estimates for the period up to 2050. International atomic energy agency. - Vienna, 2013. $-58 \mathrm{p}$.

2. Jewell J. The IEA Model of Short-term Energy Security (MOSES). Primary Energy Sources and Secondary Fuels / J. Jewell // International Energy Agency. - 2011.

3. National Energy And Utilities Regulatory Commission, Ukraine. Retrieved from: http://www.nerc.gov.ua/. 
4. Novosad V.O. Ecological component in pricing at the enterprises of heat and power generation in Ukraine: dissertation of the candidate of economic sciences / V. O. Novosad. - Sumy : Sumy State University, 2000. -203 p.

5. Pryymenko S. A. Ecological and economic assessment of energy product life cycle management : dissertation of the candidate of economic sciences/ S. A. Pryymenko. - Sumy : Sumy State University, 2015. - $215 \mathrm{p}$.

6. Shidlovskiy A. Fuel and energy complex of Ukraine on the threshold of the third millennium. A. Shidlovskiy, M. Kovalka. - K.: Ukrainian encyclopedic editions, 2001. - 400p.

7. State enterprise of Energy Markets. Retrieved from: http:/www.er.gov.ua/. 